
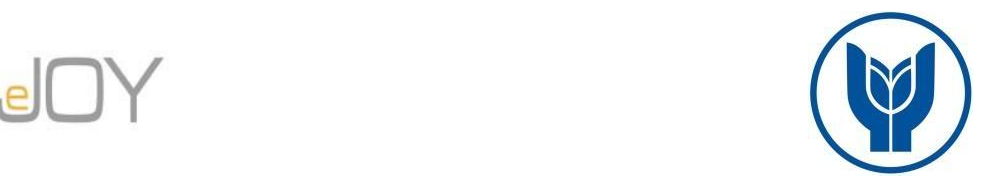

Eren Şenaras, A. / Journal of Yasar University, 2021, 16/62, 1039-1052

\title{
COVID-19 Salgınında Sağlık Çalışanlarının Enfekte Olmasına İlişkin Nedensel Döngü Diyagramı
}

\section{Causal Loop Diagram For Infection Of Healthcare Workers In The COVID-19 Outbreak}

\author{
Arzu EREN ŞENARAS, Bursa Uludağ Üniversitesi, Türkiye, arzueren@uludag.edu.tr \\ Orcid No: 0000-0002-3862-4551
}

\begin{abstract}
Öz: Tüm dünyayı etkileyen COVID-19 salgını Dünya Sağlık Örgütü (DSO) tarafindan pandemi olarak ilan edilmiştir. Ülkemizde de COVID-19 salgınına yakalanan kişi sayısı oldukça fazladır. Salgın sürecinde, ülkeler için sağlık sistemlerinin doğru politikalar geliştirilerek yönetilmesinin önemi bir kez daha ortaya çıkmıştır. Hastanelerde görevli doktor, hemşire, çeşitli sağlık çalışanları ve sağlı ekipmanları gibi kaynakların optimal kullanımının ne kadar hayati öneme sahip olduğu açıkça görülmüş̧ür. Bu çalışmanın amacl, salgın sürecinde sağlık çalışanlarının COVID-19'a yakalanma durumunda olası etkilerinin nedensel döngü diyagramıyla ortaya konmasıdır. Nedensel döngü diyagramlarının avantajları; model geliştirilirken ön taslak görevi görmeleri ve modelin tasvirini kolaylaştırmalarıdır. Dolayısıyla nedensel döngü diyagramları modelin altında yatan yapısal kabulleri hızlı bir şekilde aktarma olană̆ sağlamaktadır.
\end{abstract}

Anahtar Kelimeler: Nedensel Döngü Diyagramı, Sistem Dinamiği, Hastane Yönetimi, COVID-19 Salgını

JEL Sinıflandirması: C53, C61, C63

Abstract: The epidemic of COVID-19, which affects the whole world, has been declared by the World Health Organization (WSO) as a pandemic. In our country, the number of people suffering from COVID-19 outbreak is quite high. During the epidemic, the importance of managing health systems by developing the right policies has emerged once again. It has been clearly seen how vital the optimal use of resources such as doctors, nurses, various healthcare professionals and healthcare equipment in hospitals. The aim of this study is to reveal the possible effects of healthcare workers in the event of getting COVID-19 during the epidemic process with a causal cycle diagram. Advantages of causal cycle diagrams; they serve as preliminary drafts while developing the model and facilitate the depiction of the model. Therefore, causal cycle diagrams provide the opportunity to quickly transfer the structural assumptions underlying the model.

Keywords: Causal Cycle Diagram, System Dynamics, Hospital Management, COVID-19

JEL Classification:C53, C61, C63

\section{Giriş}

COVID-19 ilk olarak Çin'in Wuhan eyaletinde ortaya çıkmıştır. Ardından tüm dünyayı hızla etkisi altına alan COVID-19 salgını, 30 Ocak 2020 tarihinde Dünya Sağlık Örgütü (WHO) tarafından kamu sağlığı acil durumu, 11 Mart 2020 tarihinde ise evrensel salgın hastalık (pandemi) olarak ilan edilmiştir.

COVID-19 salgını, dünyada ve ülkemizde hızla yayılmış ve yaygınlaşmıştır. Bulaş özelliği yüksek olan bu salgınla mücadele kapsamında her ülke farklı politikalar izlemiştir. Salgınla mücadelede diğer ülkelerde de ülkemizde de birçok sağlık çalışanı da COVID-19 salgınından etkilenmiştir. 
OSHA (Occupational Safety and Health Administration)'nın COVID-19'a karşı önerdiği idari önlemler arasında; yüksek veya çok yüksek maruziyet riski bulunan çalışanların eldiven, önlük, yüz siperliği veya gözlükler, yüz maskesi veya respiratör kullanmaları ve çalışanların sürekli eğitimi gelmektedir (https://www.osha.gov/).

Çin'de ve diğer ülkelerde gözlendiği gibi, büyük hasta yüküyle karşı karşıya kalmak, iş yoğunluğunun artması, dinlenme sürelerinin azalması gibi konular sağlı çalışanlarının performansını etkilemektedir.

Sağlık Bakanı Fahrettin Koca, 29.04.2020 tarihinde enfekte sağlık çalışanı sayısının 7 bin 428 olduğunu açıklamıştır. Ayrıca, 1 milyon 100 bin sağlık çalışanı içinde vakalar içinde oranı \% 6,5'a yakın olduğunu vurgulamıştır. Avrupa'da bu ortalamanın \%10 - \%11 civarında olduğunu belirtmiştir (saglik.gov.tr).

Sağlık Bakanlığı tarafından hazırlanan rehber incelendiğinde; insanlar arasında COVID19'un yakın temas ve damlacıklar yoluyla bulaştığını vurgulamaktadır. Hastayla teması olanlar veya hasta bakımını yapan kişilerin, COVID-19 salgınına yakalanma riski en yüksek kişiler olduğu belirtilmiştir. Bu bağlamda, COVID-19 salgınına yakalanan hastalara bakım veren sağlık çalışanları, bu enfeksiyon açısından yüksek riskli kabul edilmekte ve sağlık çalışanlarının korunması en önemli önceliklerden biri olarak değerlendirilmektedir. Sağlık Bakanlığı tarafından hazırlanan Tablo 1'de, COVID-19 hastasıyla temas eden sağlık çalışanlarının, temas sırasında yaptıkları işlemlere ve aldıkları önlemlere göre kategorize edilerek, nasıl değerlendirilmesi gerektiği gösterilmektedir.

Tablo 1'de görüldüğü gibi, sağlık çalışanları için yaptıkları iş ve kullandığı kişisel koruyucu donanım ekipmanının varlığı dikkate alınarak; düşük, orta, yükssek riskli ve riskli değerlendirilmez olmak üzere gruplara ayrılmıştır. 
Tablo 1. Sağlık Çalışanının COVID-19 Hastası İle Temas Durumunun Değerlendirilmesi

\begin{tabular}{|c|c|c|}
\hline & $\begin{array}{l}\text { Sağlık Çalışanının Kişisel Koruyucu Ekipman (KKE) } \\
\text { kullanma durumu }\end{array}$ & Temas Riski \\
\hline \multirow{4}{*}{$\begin{array}{l}\text { Tıbbi (Cerrahi) } \\
\text { maske takılmış } \\
\text { COVıD-19 } \\
\text { hastasıyla } \\
\text { yoğun temas }\end{array}$} & $\begin{array}{l}\text { Tibbi maske veya N95 kullanmamış veya N95 } \\
\text { endikasyonu olan durumda tıbbi maske kullanmış }\end{array}$ & Orta \\
\hline & Gōz koruyucu kullanmamış & Düşük \\
\hline & Eldiven ve önlük kullanmamış & Düşük \\
\hline & Tüm KKE'yi uygun şekilde kullanmış & $\begin{array}{c}\text { Riskli } \\
\text { Değerlendirilmez }\end{array}$ \\
\hline \multirow{5}{*}{$\begin{array}{l}\text { Tibbi maske } \\
\text { takılmamış } \\
\text { COVıD-19 } \\
\text { hastası ile } \\
\text { yoğun temas }\end{array}$} & Tibbi maske veya N95 kullanmamış & Yüksek \\
\hline & $\begin{array}{l}\text { N } 95 \text { endikasyonu olan durumda tıbbi maske } \\
\text { kullanımı }\end{array}$ & Orta \\
\hline & Gōz koruyucu kullanmamış & Orta \\
\hline & Eldiven ve önlük kullanmamış & Düşük \\
\hline & Tüm KKE'yi uygun şekilde kullanmış & $\begin{array}{c}\text { Riskli } \\
\text { Değerlendirilmez }\end{array}$ \\
\hline
\end{tabular}

Kaynak:(https://covid19bilgi.saglik.gov.tr/depo/tedavi/COVID19TemasiOlanSaglikCalisanlar ininDegerlendirilmesi.pdf)

\section{Literatüre Kısa Bakış}

Alıcı vd. (2020), çalışmalarında COVID-19 salgınına ilişkin sağlık çalışanları olmak üzere, mesleki maruz kalım bakış açısı ile meslek hastalığı tanısı almaları yönünde gerekli koşulların tanımlanması, tanı sonrası yapılması gereken prosedürler, işe dönüş önerileri, özellikle sağlık çalışanlarında önleyici yaklaşımları değerlendirilmiştir.

Çetintepe ve İlhan (2020), çalışmalarında sağlık çalışanlarının COVID-19 salgınında iş sağlığı ve güvenliği ilkeleri kullanılarak mesleki bulaş risklerini azaltma yolları ve yöntemlerini incelemişlerdir. COVID-19 enfeksiyonunun sağlık çalışanları için mesleki risk oluşturduğunu, Sağlık Bakanlığı'nın ve Türkiye Halk Sağlığı Genel Müdürlüğü’nün rehberleri önderliğinde ve literatürle uyumlu kişisel koruyucu donanım kullanılması enfeksiyonun sağlık çalışanlarına bulaş riskini azalttığını vurgulamışlardır.

Eğilmez ve Yılmaz (2020) çalışmalarında, COVID-19 pandemisinde Kulak Burun Boğaz hekimlerinin karşılaşabileceği riskleri, bunlarla ilgili önlemler ve bu hastalığın seyrinde ortaya çıkabilen bazı önemli semptomları incelemişlerdir. KBB doktorlarının COVID-19 belirtileri olan hastaları görebilen ve branşının doğası nedeniyle enfeksiyon riski önemli ölçüde yüksek olan sağlık hizmeti sağlayıcıları olarak önemli bir konuma sahip olduğunu vurgulamışlardır.

\section{Sistem Dinamiği}

Sistem Dinamiği yaklaşımı 1950'li yıllarda MIT' den Jay Forrester tarafından sosyal bilimlerde, özellikle yönetimdeki karmaşık davranışların bilgisayar benzetimiyle analizi için 
geliştirilmiştir. Sistem dinamiği karmaşık sistemlerin dinamik davranışlarını anlamaya yarayan bir yöntem olarak sistem düşüncesinin bir şeklidir. Sistem dinamiğinin temelini, sistem yapılarının sistem davranışı ve sistem olaylarına nasıl yol açtıklarını anlamak oluşturmaktadır (Sezen, 2009: 298).

Sistem Dinamiğinin temel yaklaşımı, sisteme ilişkin değerleri öngörmekten çok, sistemin davranışını inceleyerek uygun politikaları tasarlamaktır. Söz konusu olan bir eniyileme işlemi değildir. Amaç incelenen sistemin belirli değişimler karşısındaki davranışını araştırmak ve bu davranışı düzenleyecek stratejileri saptayarak kararları almaktır (Erkut, 1983: 16).

Nedensel döngü diyagramları sistem dinamiği çalışmalarında iki önemli rol oynar. Birincisi, model geliştirilirken, ön taslak görevi görürler. İkincisi, nedensel döngü diyagramları modelin tasvirini kolaylaştırırlar. Dolayısıyla nedensel döngü diyagramları modelin altında yatan yapısal kabulleri hızlı bir şekilde aktarma olanağı sağlar(Goodman, 1974: 5).

\subsection{Nedensel Döngü Diyagramlart}

Geribildirim sistemlerinin etkileşimli elemanlarını haritalamanın basit bir yolu olan nedensel döngü diyagramları, 1963 yılında ilk kez Maruyama tarafından önerilmiştir. Nedensel döngü diyagramlarının amacı, dinamik bir sistemde hangi etmenin diğerinde değişime neden olduğunu göstermektir. Nedensel döngü diyagramları, sistem davranışını anlamayı denemek için sistem yapısını haritalamak amacıyla kullanılır (Sezen ve Günal, 2009: 302). Bu diyagramlar etki diyagramları olarak da adlandırılır (Wolstenholme, 1990).

İlk Sistem Dinamiği çalışmaları nedensel döngü diyagramlarını kullanmamıştır. Döngüler birikim-akış diyagramları ve denklemlerle ifade edilmiştir. Bu tür gösterimler mühendisler için doğaldır. Sistem dinamiği yaklaşımını daha geniş bir kitlenin ulaşımına açmak için nedensel döngü diyagramlarının kullanımı artarak popüler hale gelmiştir (Richardson, 1986:158). Nedensel döngü diyagramları, geribildirim sistem tasarımcıları için görsel bir araçtır (Morecroft, 2007: 39). Nedensel döngü diyagramları, modelin detaylı olarak değil de genel olarak anlaşılması amacıyla kullanılırlar. Böylece sade görünümlerini korurlar (Pidd,1996:189). Şekil 1'de nüfusun doğum ve ölüm ilişkisini gösteren nedensel döngü diyagramları gösterilmektedir. 


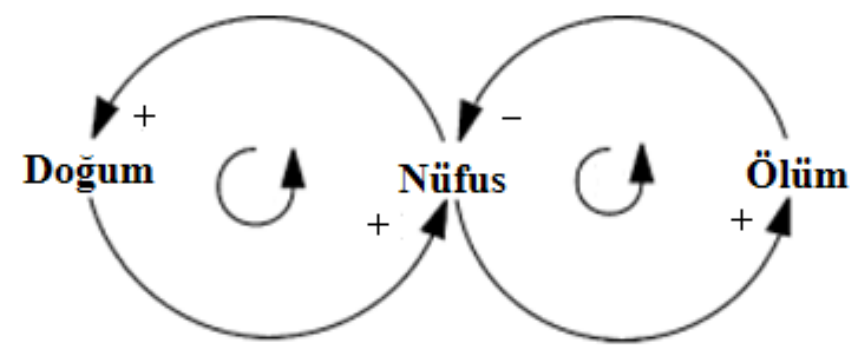

Şekil 1. Nedensel Döngü Diyagramı Örneği

Sistem dinamiği sanatının büyük kısmı geribildirim süreçlerini keşfedip göstermektir. Bu sayede stoklar ve akışlar, zaman gecikmeleri, doğrusal olmayanlar sistemin dinamiğini belirler (Sterman, 2000:12). Sistem içerisinde var olan değişkenlerin birbirleriyle olan ilişkilerini ve birbirleri üzerindeki etkilerini göstermek için nedensel döngü diyagramları kullanılmaktadır.

$\mathrm{Bu}$ diyagramlar sözel olarak tanımlamanın zor olduğu ilişkileri ortaya koymak için kullanılır. Çünkü normal anlatımla doğrusal neden-sonuç ilişkisi tanımlanırken bu diyagramlar ile gerçek sistem ilişkisi olan döngüsel neden-sonuç ilişkileri tanımlanır (Kirkwood, 1998: 5).

Nedensel döngü diyagramları sistem dinamiği çalışmalarında iki önemli rol oynar. Birincisi, model geliştirilirken, ön taslak görevi görürler. İkincisi, nedensel döngü diyagramları modelin tasvirini kolaylaştırırlar. Dolayısıyla nedensel döngü diyagramları modelin altında yatan yapısal kabulleri hızlı bir şekilde aktarma olanağı sağlar (Goodman, 1974: 5).

Kapalı döngü, bir bardağı su ile doldurmak gibi basit bir örnekle Şekil 2'de gösterilmiştir.

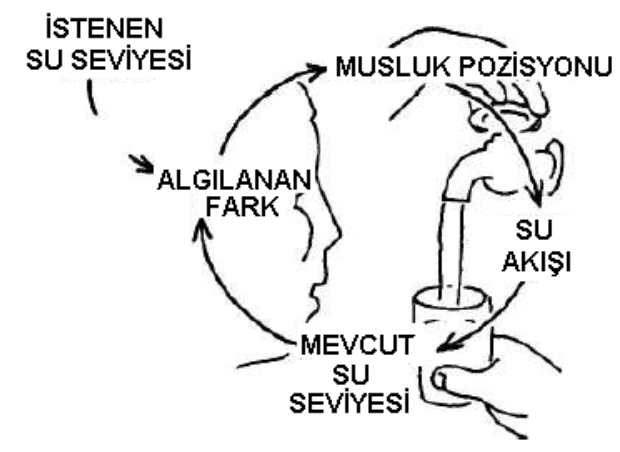

Şekil 2. Bardak Örneğinin Görsel İfadesi

Kaynak: Senge, 1994: 60

Nedensel bağlantılar ampirik araştırmalar ile veya resmi kayıtlar ile oluşturulabilir (Weber, 2010: 10). Şekil 3’te görülen diyagramda nedensel bağlantılar (elementler ve oklar) 
bulunmaktadır. Ayrıca bu okların üzerinde + ve - işaretleri göze çarpmaktadır. Bu işaretlerin anlamları aşağıdaki gibidir:

1) Eğer A'daki bir değişim ve B'de aynı yönde bir değişime neden oluyorsa veya $A$, B'ye ekleniyor ise, bir A elemanından B elemanına olan nedensel bağlantı (ok) pozitiftir (+).

2) Eğer A'daki bir değişiim ve B'de ters yönde bir değişime neden oluyorsa veya A, B'den çıkartılıyor ise, bir A elemanından B elemanına olan nedensel bağlantı (ok) negatiftir (-).
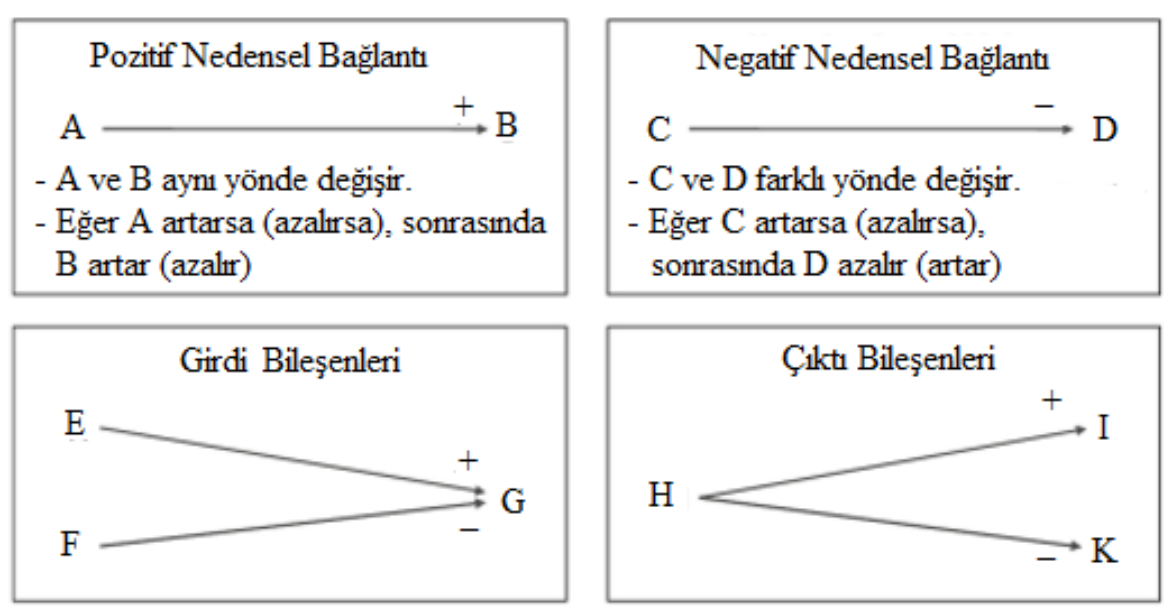

Şekil 3. Nedensel Bağlantılar

Kaynak: Weber, 2010: 10

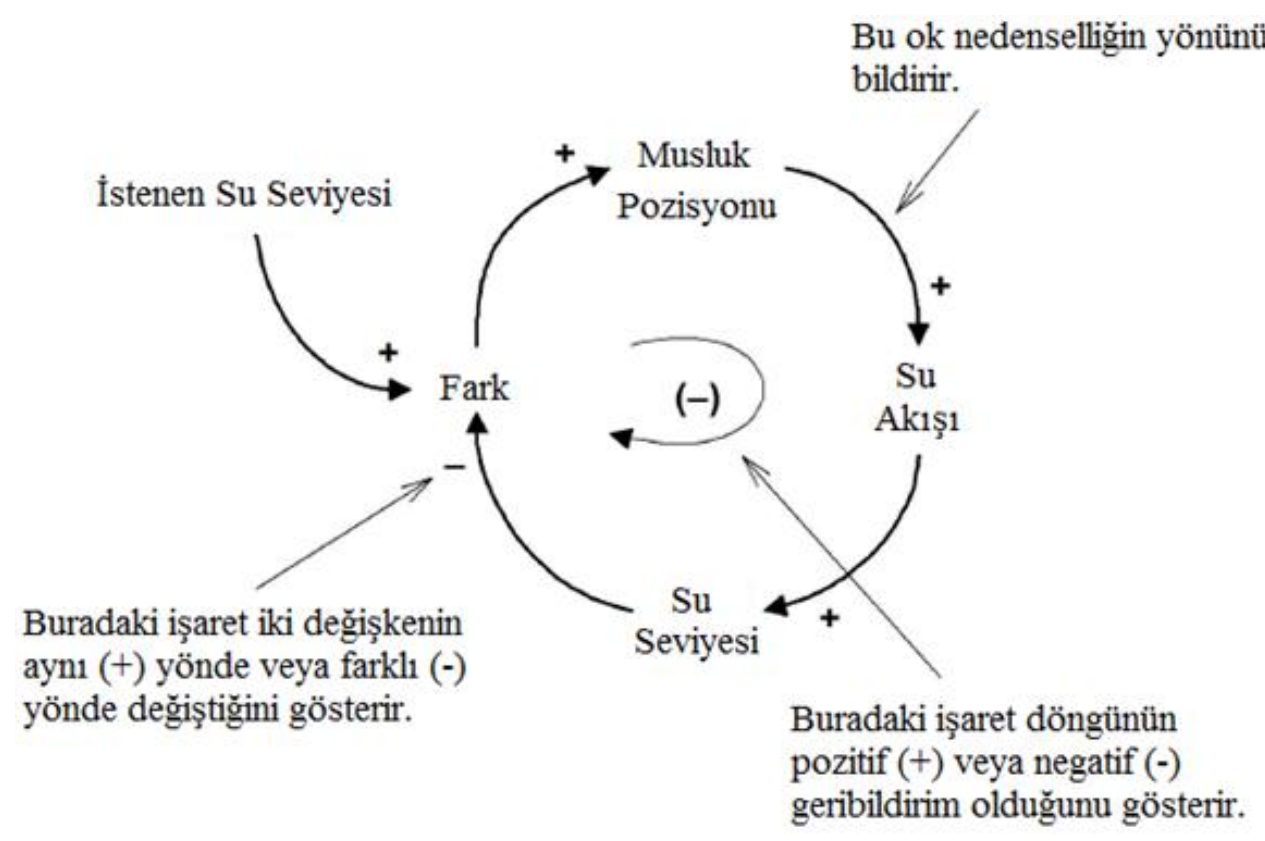

Şekil 4. Nedensel Döngü Diyagramı: Kapalı Döngü

Kaynak: Kirkwood, 1998:8 
Şekil 4'teki örneği ele alacak olursak, musluğun pozisyonu yükseldiğinde (musluk daha fazla açıldığında) su akışı artacaktır. Bu yüzden musluk pozisyonuyla su akışı pozitiftir. Aynı şekilde su akışı arttığında su seviyesi artacaktır. Su akışıyla su seviyesi arasındaki bağlantı bu sebeple pozitiftir.

Fark $=$ İstenen su seviyesi - Su seviyesi

$\mathrm{Bu}$ tanımdan eğer su seviyesi artarsa fark azalır, dolayısıyla aralarındaki fark negatiftir. Son olarak döngüyü kapatmak için musluk pozisyonuyla fark arasında pozitif bir ilişki vardır. Fark ne kadar fazlaysa musluğu o kadar fazla açarız. Burada istenen su seviyesi ile fark arasındaki ilişki pozitiftir. Bağlantıların üzerindeki her bir işarete ek olarak döngünün de bir işareti vardır. Döngü için işaret döngüyü oluşturan negatiflerin (-) toplamı ile belirlenir.

1) Eğer negatif nedensel bağlantı(ların) sayısı çift sayı ise, geribildirim döngüsü pozitif olarak adlandırılır ve $(+)$ işareti ile gösterilir.

2) Eğer negatif nedensel bağlantı(ların) sayısı tek sayı ise, geribildirim döngüsü negatif olarak adlandırılır ve (-) işareti ile gösterilir (Kirkwood, 1998: 8).

Benzer şekilde Barlas (2015), bir döngünün işaretini döngünün çevresindeki tüm işaretlerin çarpımı olarak ifade etmektedir.

Pozitif ve negatif olmak üzere iki tür döngü olduğu söylenebilir. Bunlardan ilki olan “pozitif”, aynı zamanda "pekiştirici” olarak ta adlandırılmaktadır. Şekilde “+” işaretiyle gösterilmiştir. Endüstri kolunda büyüme gerçekleştiğinde, sermaye birikimini artırmakta, artan sermaye birikimi de endüstri kolunun büyümesini sağlayarak pekiştirerek büyüyen bir döngü söz konusu olacaktır. Diğeri ise "negatif”, aynı zamanda “dengeleyici” olarak da adlandırılmaktadır. Şekilde “_” işareti ile gösterilmişlerdir. Örnek olarak, endüstri kolunun büyümesiyle işgücü ihtiyacı artacaktır. Bunun sonucunda kullanılabilir işgücü miktarı azalacaktır. Azalan kullanılabilir işgücü miktarı ise endüstri kolunun büyümesine ket vurmakta (örneğin, ücretlerdeki artış nedeniyle), dolayısıyla bu büyümeyi dengelemektedir (Saysel ve Barlas, 2001: 8).

\subsubsection{Pekiştirici (Pozitif) Geribildirim Döngüleri}

Pozitif geribildirimde, meydana gelen değişim süreç değişikliğine sebep olan bileşenin değişimini güçlendirecek yönde etki meydana getirir. Örneğin; kendinizi iyi hissederseniz ve kendinizin bir alanda iyi olduğunu düşünürseniz çok çalışırsınız çünkü çok çalıştıkça daha başarılı olursunuz, bu da sizin kendinizi daha iyi hissetmenize sebep olur ve o alanda başarılı olma şansınızı arttırırsınız (McGarvey ve Hannon, 2003: 6). 
Şekil 5'te görünen banka bakiyesinin, faizinin hesapta bırakılarak artması da örnek olarak gösterilebilir

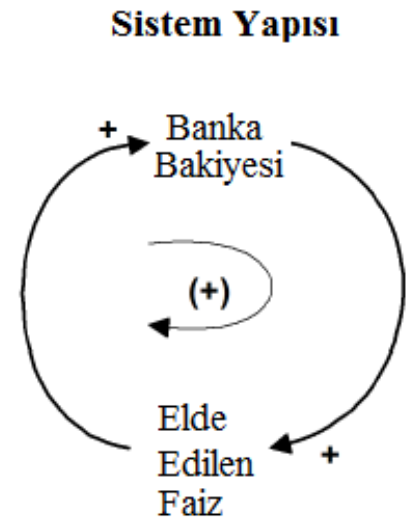

\section{Davranıș Șekli}

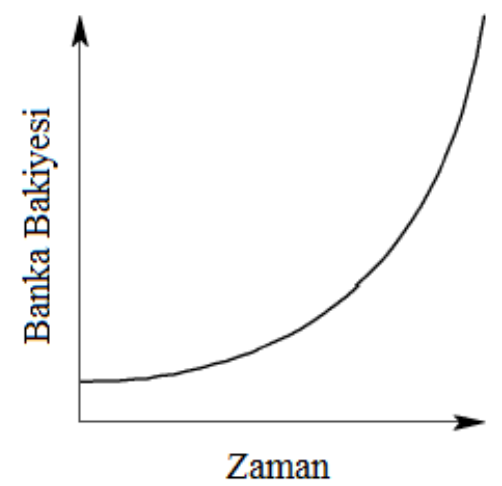

Şekil 5. Pozitif (Pekiştirici) Geribildirim Döngüsü: Banka Bakiyesi Büyümesi Kaynak: Kirkwood, 1998: 10

Pozitif geribildirim döngüsü, kendi kendini güçlendirici değişimleri yaratan bir neden sonuç ilişkileri zinciridir. Pozitif geribildirim döngüsündeki herhangi bir elemanda meydana gelen bir değişim diyagram üzerindeki diğer elemanları etkileyerek en sonunda kendisi üzerinde de değişim ile aynı yönde etki yaratır. Bir artış yeni artışlara neden olurken, bir azalış da yeni azalışlara sebep olacaktır (Meadows vd., 2006: 25).

\subsubsection{Dengeleyici (Negatif) Geribildirim Döngüleri}

Dengeleyici bir sistemde belli bir amacı korumaya çalışan bir kendi kendini kontrol etme mekanizması vardır. Bir arabayı direksiyonla idare etmek veya bisikletin üzerinde durmak bir dengeleme süreci örneğidir. Bunlarda amaç istenen bir yöne gitmektir (Senge, 2002). Bir bileşendeki değişim başka bir bileşeni ters yönde etki edecek şekilde cevap veriyorsa geribildirimin negatif (dengeleyici) olduğu ifade edilir (Morecroft, 2012: 8). Dengeleyici geribildirim, kendini düzelten sistem olarak da ifade edilir. Sistem gerçekleşen ile hedeflenen arasındaki uyumsuzluğu fark eder, bunu düzeltmek için çeşitli eylemlerde bulunur ve sistem dengelenir. $\mathrm{Bu}$ tür geribildirimde, sistem içindeki bir değişken diğerini arttırsa bile diğer değişken söz konusu değişkenin azalması yönünde bir davranış gösterir (Sterman, 2000: 107109).

Şekil 6'da yer alan nakit döngüsü dengeleyici geribildirim döngüsüne örnek verilebilir. 


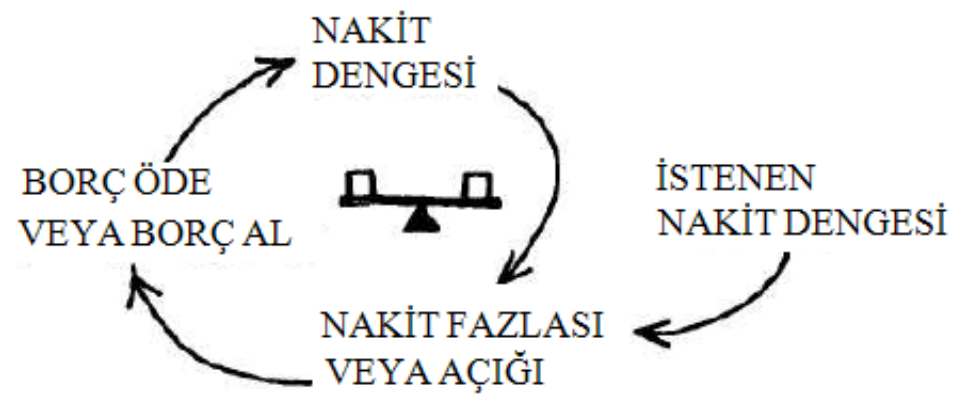

Şekil 6. Dengeleyici Geribildirim Döngüsü: Nakit Döngüsü

Kaynak: Senge, 2004: 72

Dengeleyici geri bildirim, bir hedef arar. Eğer ilgilenilen değişkenin mevcut değeri hedeflenen değerin üstündeyse, döngü yapısı değişkenin değerini aşağıya çeker; eğer değişkenin mevcut değeri, hedef değerin altındaysa döngü yapısı, değişken değerini arttırır. Birçok yönetim süreci geribildirim döngüleri içererek; yararlı bir istikrar sağlarken aynı zamanda gereken değişimlere de direnç gösterir. Dış çevrenin, organizasyonel değişimi dikte ettiği durumlarda benzer davranışlar sergilemeye devam eder. Bu tip geribildirim davranışları bazı organizasyonlarda o kadar güçlüdür ki organizasyon değişim yerine sektör dışı kalmayı tercih edebilir (Kirkwood, 1998: 10).

\subsubsection{Pozitif ve Negatif Geribildirimlerin Kombinasyonu}

Pozitif ve negatif geribildirimler kombine edildiğinde olası birçok davranış gözlenebilir. Şekil 7'te yer alan örnekte önce pozitif geribildirim üssel büyümeye sebep olmakta, daha sonra negatif geribildirim sistem davranışını yönetmeye başlamaktadır (Kirkwood, 1998: 12).

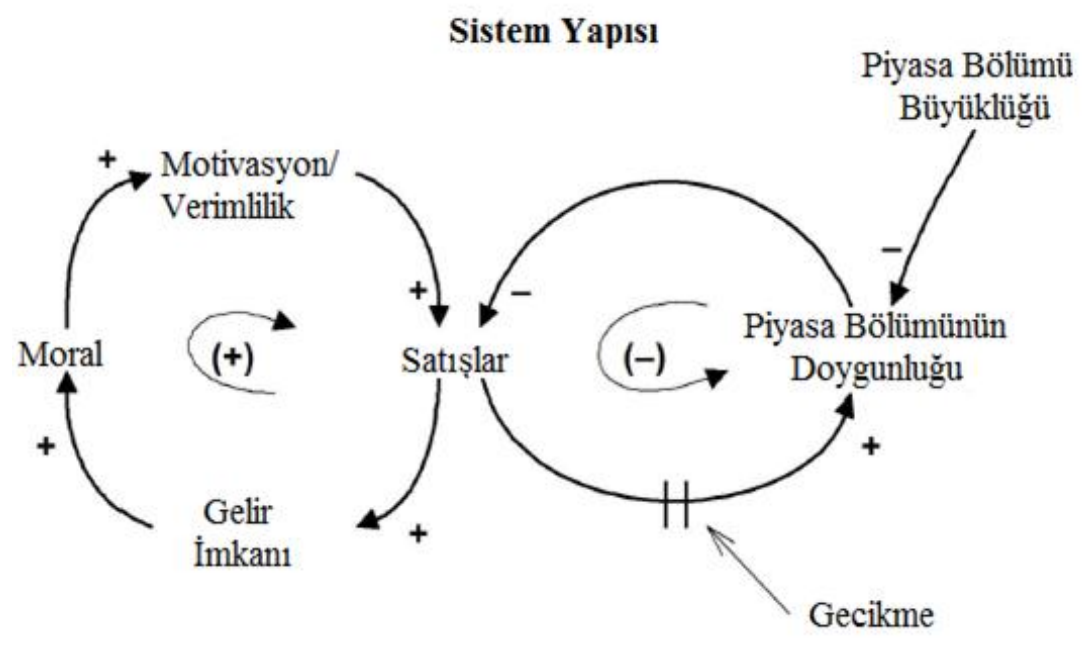

Şekil 7. Pozitif ve Negatif Geribildirimlerin Kombinasyonu: Satışların Büyümesi 


\section{Davranıș Șekli}

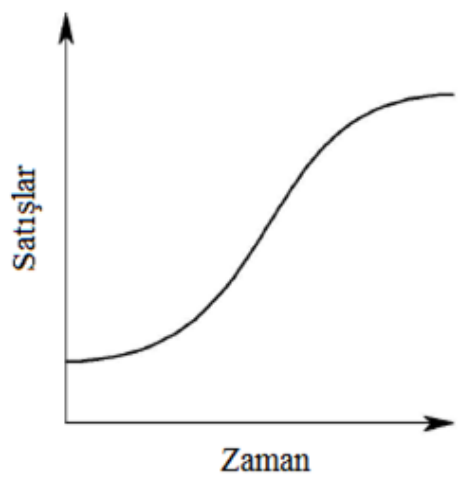

\section{Şekil 8. Satışların Büyümesi Grafiği}

Nedensel döngü diyagramlarını oluşturmaya başlamak için hangi olayların sistem yapısını daha iyi anlaşılmasını sağladığının belirlenmesi gerekir. Richardson ve Pugh (1981) ve Kim (1992) tarafindan kaleme alınan nedensel döngü diyagramlarının oluşturulması için ipuçları aşağıdaki gibidir:

1) Nedensel döngü diyagramında yer alan elemanları artabilen veya azalabilen değişkenler olarak düşünün, eğer bu değiş̧kenlerin büyüklüklerini ölçemiyorsanız kaygılanmayın.

- Elemanları tanımlamak için isim veya isim cümlesi kullanılmalıdır. Eylemler oklarla (bağlantılarla) gösterilir. Örneğin, "artan maliyet" yerine "maliyet" kullanılmalıdır.

- Elemanların tanımlanması açıkça belirtilmelidir, hangi yönde arttığı açıkça belli olsun.

- Genel olarak eleman isimlerinin pozitif yönde olacak şekilde seçilmesi daha açıklayıcı olur. Örneğin, “daralma” yerine "büyüme” kullanılmalıdır.

- Nedensel bağlantılar sadece zamanlamayı göstermemeli aynı zamanda nedensellik yönünü de belirtmelidir. A elemanından B elemanına pozitif bir bağlantı önce A olur sonra B olur değil, A artınca B artar anlamı taşır.

2) Diyagramdaki bağlantıları oluştururken beklenmedik olası yan etkilerin meydana gelebileceğini ve çizilenleri etkileyebileceklerini düşünün.

3) Negatif geribildirim döngüleri için bir hedef vardır. Bu hedef ve mevcut durumla arasındaki fark gösterilirse çok daha açıklayıcı olacaktır. Elektrikli battaniye örneğinde olduğu gibi hedeflenen değer ve farkın gösterilmesi sistemi daha anlaşılır kılacaktır. 
4) Sistemin algılanan ve mevcut durumları arasındaki fark sistem davranışını anlatmak için önem taşır. Bu yüzden sistemi nedensel döngü elemanı olarak hem değişkenin mevcut değerini hem de algılanan değerini dâhil etmek önemli olabilir. Birçok durumda, mevcut durum algılanana kadar gecikme meydana gelir. Örneğin, mevcut ürün kalitesinde değişim olduğunda, bu değişimin müşteriler tarafindan algılanması zaman alır.

5) Eylemlerin kısa dönem ve uzun dönem sonuçları arasında farklar vardır. Bunların farklı döngüler yardımıyla ayrılması gerekir.

6) Eğer iki eleman arasında çok fazla açıklama gerekiyorsa bu iki element arasına ara bir element eklenmesiyle sistem yapısı daha açık bir şekilde ortaya konabilir.

7) Yukarıdaki maddeleri de göz önünde bulundurarak diyagramı olabildiğince basit tutun. $\mathrm{Bu}$ diyagramların amacı, tüm yönetim sürecini detaylarıyla tanımlamak değil, gözlenen sistem davranışını oluşturan tüm geribildirim yapılarını ortaya koymaktır (Kirkwood, 1998: 13-14).

\section{COVID-19 Salgınında Sağlık Çalışanlarına İlişkin Nedensel Döngü Diyagramı}

Tüm dünyayı etkisi altına alan COVID-19 pandemisi ülkemizde de birçok kişinin enjekte olmasına sebebiyet vermiştir. Salgın sürecinin yönetiminde çok önemli rolü olan sağlık çalışanlarının salgından etkilenerek sahadan ayrılmak durumunda kalması, sağlık sistemini etkileyerek salgınla mücadeleyi zorlaştırmaktadır. $\mathrm{Bu}$ bağlamda, enjekte olan sağlık çalışanlarının, sağlık sistemi üzerine etkilerinin incelenmesi oldukça önemli bir konudur. $\mathrm{Bu}$ çalışmanın amacı, salgın sürecinde sağlık çalışanlarının COVID-19'a yakalanma durumunda olası etkilerinin nedensel döngü diyagramıyla ortaya konmasıdır. Nedensel döngü diyagramlarının avantajları; model geliştirilirken ön taslak görevi görmeleri ve modelin tasvirini kolaylaştırmalarıdır. Dolayısıyla nedensel döngü diyagramları modelin altında yatan yapısal kabulleri hızlı bir şekilde aktarma olanağı sağlamaktadır.

Sağlık çalışanlarının COVID-19 ile enfekte olmalarının sağlık sistemi üzerine etkisi örneğine ilişkin nedensel döngü diyagramı Şekil 9'daki gibidir. Nedensel döngü diyagramı Vensim PLE yardımıyla oluşturulmuştur. 


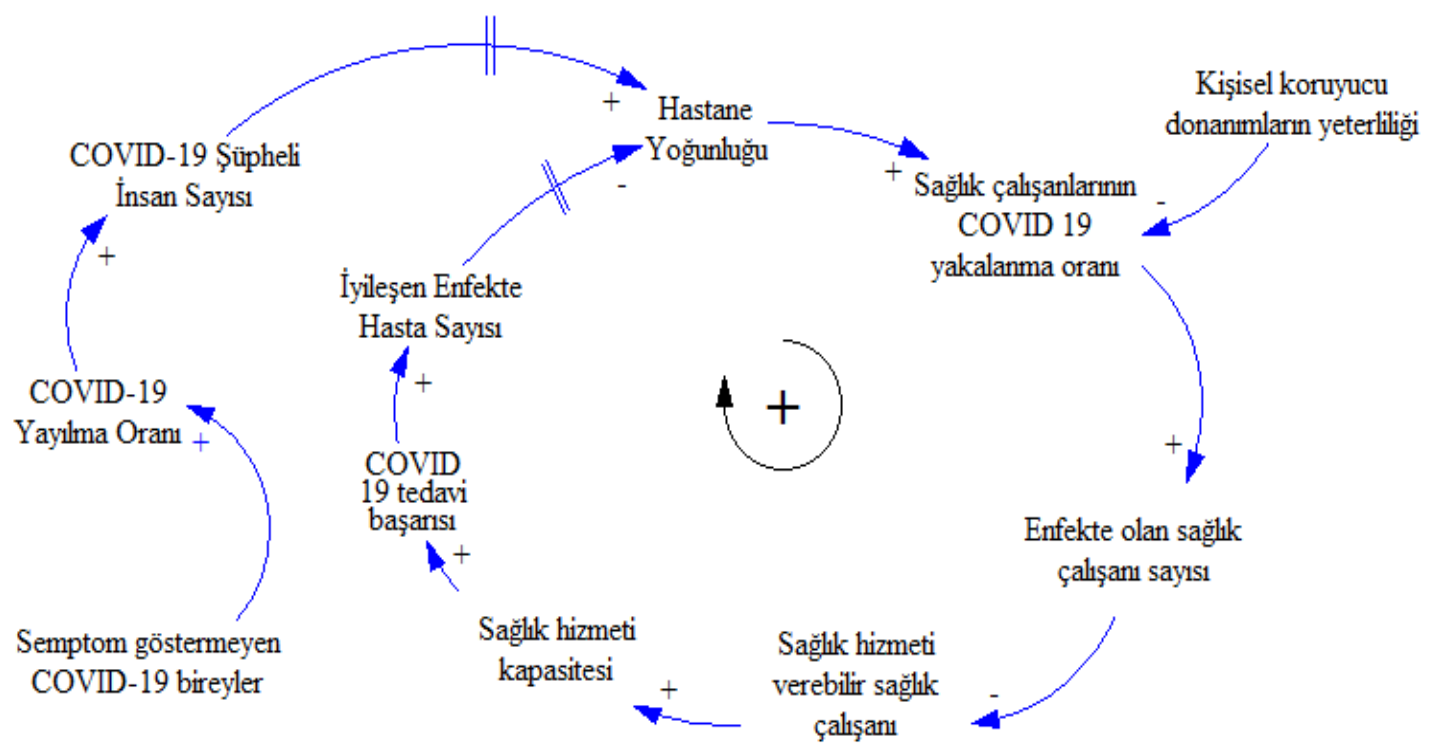

Şekil 9. Nedensel Döngü Diyagramı: Sağlık Çalışanlarının COVID-19 ile Enfekte Olmalarının Sağlık Sistemi Üzerine Etkisi Örneği

Şekil 9 incelendiğinde; semptom göstermeyen COVID-19 bireylerin artması, COVID-19 yayılma oranını yükseltecektir. COVID-19 yayılma oranının yükselmesi (azalması) COVID-9 şüpheli insan sayısını arttıracaktır (azaltacaktır). Aynı yönde değişimden söz edildiği için okun üzerine “+” işareti eklenmiştir. COVID-19 şüpheli sayısı artması, hastane yoğunluğunu arttıracaktır. Hastane yoğunluğunun artması, sağlık çalışanlarının COVID-19'e yakalanma oranını arttırırken, kişisel koruyucu donanımların yeterliliği sağlık çalışanlarının COVID-19 yakalanma oranını azaltacaktır. Yakalanma oranının artması, enfekte olan sağlık çalışanı sayısını arttırır. Sağlık çalışanlarının enfekte olması durumunda sağlık hizmeti veremez duruma gelecektir. Bu durumda enfekte olan sağlık çalışanının artması, sağlık hizmeti verebilir sağlık çalışanı sayısını azaltır. Burada ters yönde bir değişim olması sebebiyle (A artarken B azalır veya A azalırken B artar) okun üzerinde “-” işareti yazılmıştır. Sağlık hizmeti kapasitesi kavramının kapsamını, çalışabilir sağlık personeli oluşturmaktadır. Bu bağlamda, sağlık hizmeti verebilir sağlık çalışanının artması sağlık hizmeti kapasitesini arttırır. Sağlık hizmeti kapasitesinin artması, COVID-19 tedavi başarısını arttırır. COVID-19 tedavi başarısının artması, iyileşen enfekte hasta sayısını arttırır. İyileşen hasta sayısının artması, hastane yoğunluğunu azaltır.

Bir değişim olduğunda, diğer bir değişken üzerinde etkisi belli bir gecikme ile meydana gelebilir. Okların üzerinde yer alan "çift çizgi" gecikmeleri göstermektedir. Ele alınan sistemde COVID-19 şüpheli insan sayısının artması, bir süre sonra hastane yoğunluğunun artmasına sebebiyet verecektir. Ayrıca, ele alınan nedensel döngü diyagramı pozitif 
geribildirim döngüsüdür. Buna, pekiştirici geribildirim döngüsü de denebilir. Nedensel döngü diyagramının içerisinde yer alan “+” işareti ile döngünün, negatif veya pozitif geribildirim döngüsü olduğunu gösterebiliriz.

\section{Sonuç}

Sağlık sistemlerinin yönetilmesinde, sağlık çalışanları ve ekipmanların yeterliliğinin önemi açıktır. Mevcut kaynakların optimal kullanımı, özellikle COVID-19 salgınının yönetilmesinde oldukça önemlidir. Bu bağlamda, oluşturulan nedensel döngü diyagramının sistem üzerinde birbirini etkileyen unsurları açıkça ortaya koyduğu görülmektedir. Nedensel döngü diyagramı, sistem davranışını anlamamızı sağlar. Ayrıca, Vensim PLE'de oluşturulan nedensel döngü diyagramı, sonraki çalışmaların konusunu oluşturacak salgın dönemlerinde sağlık sistemi kaynaklarının yeterliliğini sistem dinamiği ile incelenmesine 1şık tutacaktır.

Sonraki çalışmaların konusu; incelenen nedensel döngü diyagramından hareketle Sistem Dinamiği modeli geliştirilmesidir. Geliştirilecek Sistem Dinamiği modeli sayesinde, sağlık çalışanlarının enfekte olma durumunun sistem üzerine etkileri incelenebilir. Sağlık çalışanlarının COVID-19 enfekte durumuna bağlı olarak sistemin davranışını nasıl etkilediği incelenerek farklı politikaların geliştirilmesi sağlanabilir. 


\section{KAYNAKÇA}

Alıcı N. Ş., Beyan A. C., Şimşek C., (2020), “Meslek Hastalığı Olarak COVID-19”, Eurasion Journal of Pulmonogy", Ek Say1-COVID19 148-165.

Çetintepe S, İlhan M. (2020), "COVID-19 Salgınında Sağlık Çalışanlarında Risk Azaltılması”, Journal Biotechinol \& Strategic Health Research; 4: 50-54.

Eğilmez, O, Yılmaz, M. (2020), "Kulak Burun Boğaz Hekimliği Açısından COVID-19 Salgını”. Journal of Biotechnology and Strategic Health Research, 4 () , 140-146. DOI: 10.34084/bshr.724587

Erkut Haluk (1983), Sistem Dinamiğinin Temelleri, İTÜ Fen Edebiyat Fakültesi Ofset Atölyesi, İstanbul.

Goodman M.R. (1974), Study Notes In System Dynamics, Wright Allen Press Inc.

Jiancong W., Mouqing Z., Fangfeı L..(2020), Exploring The Reasons For Healthcare Workers Infected With Novel Coronavirus Disease 2019 (COVID-19) in China. The Journal Of Hospital Infection. DOI: https://doi.org/10.1016/j.jhin.2020.03.002

Kirkwood Craig W. (1998), System Dynamics Methods: A Quick Introduction, College Of Business Arizona State University. http://www.public.asu.edu/ kirkwood/sysdyn/SDIntro/SDIntro.htm

Morecroft J. (2015), Strategic Modelling And Business Dynamics: Approach, John Wiley \& Sons, Chichester, England.

Pidd M. (1996), Tools for Thinking Modelling in Management Science, John ～Wiley \& Sons, Chichester, England.

Richardson G.P.,(1999), Feedback Throught in Social Science And Systems Theory, Pegasus Communications, Inc, Waltham.

Goodman M.R. (1974), Study Notes In System Dynamics, Wright Allen Press Inc.

Mcgarvey B., Hannon B. (2003), Dynamic Modelling For Business Management An Introduction, Springer Press, USA.

Meadows D., Randers J, Meadows D. (2006), Limits To Growth, Bath Press, London, UK.

Saysel A. K. - Barlas Y. (2006), "Model Simplification and Validation with Indirect Structure Validity Tests", System Dynamics Review, Cilt 22, No. 3.

Senge P.. M. (2002), Beşinci Disiplin, Çeviren: Ayşegül İldeniz Ve Ahmet Doğukan, Yapı Kredi Yayınları, 16.Bask1, İstanbul.

Senge P. (1990), The Fifth Discipline: The Art And Practice Of The Learning Organization. Random House, London.

Sezen H. Kemal., Günal Murat. (2009), Yöneylem Araştırmasında Benzetim, Ekin Yayınevi, Bursa.

Sterman, J.D. (2000), Business Dynamics Systems Thinking And Modelling In A Complex World, McgrawHill, New York. http://www.simposio.palmira.unal.edu.co/documentos/Sterman_Business_dynamics.pdf

Weber L. (2010), Demographic Change and Economic Growth Simulations on Growth Models, Springer Verlag Berlin.

Wolstenholme, E.F. (1990), Systems Enquiry: A System Dynamics Approach. John Wiley \& Sons, Chichester, England.

https://www.toraks.org.tr/halk/news.aspx?detail=5768

https://www.osha.gov/

https://covid19bilgi.saglik.gov.tr/depo/tedavi/COVID19TemasiOlanSaglikCalisanlarininDegerlendirilmesi.pdf (Erișim tarihi: 05.05.2020) 